\title{
The limited influence of neurosurgeons' behavior on inpatient satisfaction: a retrospective multihospital analysis
}

\author{
Christine Park, BA, ${ }^{1}$ Rasheedat T. Zakare-Fagbamila, MD, ${ }^{2}$ Wes Dickson, BSE, ${ }^{3}$ \\ Alessandra N. Garcia, PhD, PT, ${ }^{4}$ and Oren N. Gottfried, MD ${ }^{1}$ \\ 1Department of Neurosurgery, Duke University Medical Center, Durham, North Carolina; ${ }^{2}$ Department of Neurosurgery, University \\ of Florida Health, Gainesville, Florida; ${ }^{3}$ Department of Performance Services, Duke University Health System, Durham; and \\ ${ }^{4}$ Division of Doctor of Physical Therapy, Department of Orthopaedic Surgery, Duke University, Durham, North Carolina
}

\begin{abstract}
OBJECTIVE The Hospital Consumer Assessment of Healthcare Providers and Systems (HCAHPS) is a survey that assesses patient satisfaction, which is an important measure of the quality of hospital care and ultimately the overall hospital rating (OHR). However, the survey covers several elements of patient satisfaction beyond the patient-surgeon interaction. In this study, authors investigated which admission and experience factors had the highest impact on the OHR.

METHODS This was a retrospective cohort analysis of HCAHPS surveys from patients who, in the period between August 1, 2016, and January 31, 2018, had been discharged from the neurosurgical or orthopedic service at three hospitals serving a single metropolitan area. The top-box score was defined as the highest rating obtainable for each survey question. Baseline admission attributes were obtained, and multivariate logistic regression was used to determine predictors of the top-box OHR.
\end{abstract}

RESULTS After application of the inclusion and exclusion criteria, 1470 patients remained in the analysis. Categories on the HCAHPS included OHR, communication, education, environment, pain management, and responsiveness. After excluding identifying questions from the survey and adjusting for subspecialty and hospital, 7 of 17 HCAHPS survey items were significant predictors of OHR. Only 2 of these were related to the surgeon: 1) discharge, "Did you get information in writing about what symptoms or health problems to look out for after you left the hospital?" (OR 5.93, 95\% Cl 2.52-13.94); and 2) doctor, "Did doctors explain things in a way you could understand?" (OR 2.78, 95\% Cl 1.73-4.46). The top three strongest correlating items were 1) discharge; 2) nursing, "Did nurses treat you with courtesy and respect?" (OR 3.86, 95\% Cl 2.28-6.52); and 3) hospital environment, "Were your room and bathroom kept clean?" (OR 2.86, 95\% $\mathrm{Cl} 1.96-4.17)$.

CONCLUSIONS The study findings demonstrated that there are several nonmodifiable factors (i.e., specialty, experience) and items that are not under the direct purview of the neurosurgeon (e.g., nursing communication, hospital environment) that are significant influences on overall inpatient satisfaction on the HCAHPS survey. Furthermore, components of the survey that ultimately influence the OHR vary across different hospitals. Hence, HCAHPS survey results should be broadly interpreted as a way to make health systems more aware of the overall hospital factors that can improve quality of care and patient experience.

https://thejns.org/doi/abs/10.3171/2020.5.JNS20923

KEYWORDS patient satisfaction; patient-reported outcomes; communication; HCAHPS; behavior

I N 2013, the assessment of hospital quality for all specialties, including neurosurgery, transitioned from the Press Ganey survey to the Hospital Consumer Assessment of Healthcare Providers and Systems (HCAHPS). ${ }^{1}$ The HCAHPS survey is now the most widespread measure of inpatient satisfaction in the United States. It is a 31-item survey that is mailed, emailed, or called in to pa- tients soon after they are discharged from the hospital and evaluates their experiences, including an overall hospital rating (OHR). Considering that patient satisfaction is an important indicator of hospital care quality, collecting this measure can raise potential solutions and opportunities to improve hospital care., ${ }^{2,3}$ A previous systematic review investigating instruments to measure patient satisfaction

ABBREVIATIONS HCAHPS = Hospital Consumer Assessment of Healthcare Providers and Systems; OHR = overall hospital rating .

SUBMITTED March 24, 2020. ACCEPTED May 4, 2020.

INCLUDE WHEN CITING Published online July 31, 2020; DOI: 10.3171/2020.5.JNS20923. 
with healthcare quality in hospitals has highlighted the HCAHPS as a reliable and valid measure strongly recommended for use for high-stakes purposes (e.g., financial incentives or an outcome measure in a research study). ${ }^{3}$

The Centers for Medicare \& Medicaid Services (CMS) requires all hospitals in the United States to report HCAHPS findings, which are used as a proxy for the quality of hospitals to calculate Medicare reimbursements and compensations. ${ }^{4,5}$ Although there are financial incentives that directly affect the neurosurgeon, the 31 survey items cover a broad range of domains including OHR, communication with doctors ("Doctor") and nurses ("Nursing"), medications ("Medication"), discharge education ("Discharge"), hospital environment ("Environment"), pain management ("Pain"), and responsiveness to needs ("Responsiveness"). ${ }^{6}$

Because there are many other components to the questionnaire, we sought to clarify the drivers of the overall rating using de-identified patient responses to the HCAHPS in conjunction with hospital admissions data. Using the OHR as the outcome measure in this study, we attempted to determine 1) the baseline admission-specific predictors of the OHR, 2) the HCAHPS items most strongly associated with a good OHR, and 3) methods to improve the assessment of neurosurgeons based on these findings.

\section{Methods}

\section{Study Design and Setting}

This IRB-exempt study was a retrospective cohort analysis of returned HCAHPS surveys from patients who had been discharged from our health system between August 1, 2016, and January 31, 2018. Study results were reported using the STROBE statement?

\section{Participants}

Included for analysis were all patients who 1) had been admitted under a neurosurgeon or an orthopedic spine surgeon; 2) had been hospitalized in one of the three main hospitals within the health system: university hospital (hospital 1) = large (957 beds) academic hospital, regional hospital (hospital 2) = medium (369 beds) community hospital, city hospital (hospital 3 ) = small (186 beds) community hospital; and 3) had been eligible for and returned the HCAHPS survey. Patients eligible for the survey were those over the age of 18 years who were admitted for at least 1 complete night, did not have a primary psychiatric diagnosis, and were not discharged to a nursing home or hospice. ${ }^{8}$ Excluded patients were those who did not answer the OHR item.

\section{Variables}

Patient HCAHPS responses as well as their discharge month, hospital, surgeon, and discharging service were obtained from Performance Services-a department responsible for collecting routine business performance metrics such as feedback and demographic data at the individual patient, provider, and hospital level. For each attending, their sex and years of experience were collected from their online institutional profiles. National averages for the HCAHPS scores were also available from Medicare and HCAHPS online reports for comparison. ${ }^{6,9}$

For each patient, de-identified responses to 17 of the 31 survey items (Table 1) were made available from our Performance Services database, as were their discharge month, hospital, attending, and discharging service. The 14 HCAHPS items excluded from our analysis were identifying data or did not materially add to the analyses (e.g., "Would you recommend this hospital to your friends and family?"). The attending physician of each patient was linked to their sex and years of experience, and these variables were added to the analysis.

The HCAHPS is a multiple-choice survey, but providers and hospitals only receive credit for the best responses, called "top-box" responses; therefore, each of the responses to each question was recoded as a binary, with top-box answers (score of 10 or 9 for numeric questions, "always" for Likert questions, or "yes" for yes/no questions) assigned a score of 1 and all other answers assigned a score of 0 . The percentage of top-box answers for each question item was recorded as the variable "top box." Questions within the domain of communication with doctors (Doctor) or discharge communication (Discharge) were considered to be under the direct purview of the surgeon or surgical team, and all other questions were considered not to be.

\section{Statistical Considerations}

Descriptive statistics (frequencies, means, and percentages) were used to summarize the surgeon characteristics at baseline. For the outcome measure, OHR, the degree of influence of a variable or survey item on the OHR was calculated as the odds ratio of receiving a top-box OHR given a specific value for that variable or a top-box score for that item. The odds ratios were derived from multivariate logistic regressions with OHR as the outcome. The first regression looked at the hospital admission variables (i.e., admitting hospital, department, subspecialty, patient sex, and month) as predictors of OHR in order to determine baseline differences in OHR between hospitals, specialties, and subspecialties. The second regression looked at the HCAHPS questions as predictors, adjusting for hospital admission variables based on the first analysis, and backward elimination was used to arrive at the final model for the questions that were the greatest determinants of the OHR with a minimum $\mathrm{p}_{\text {out }}=0.05$. To investigate confounding, additional post hoc tests were run, including a beta regression to determine if the response rate to an item was influenced by the score. We also separated our cohort by hospital to determine if patients within the different hospitals assigned differing weights to specific HCAHPS items as related to the OHR.

The major source of bias in the study was nonresponse bias from incomplete surveys, so the questions that had nonresponse rates greater than 15\%-two medication communication questions and one responsiveness question-were eliminated from consideration in the model (Table 1). There has been no documented need to add nonresponse weights to individual items. ${ }^{10}$ The nonresponse bias related to the relatively low rates of response to the survey at all is well documented in the literature; therefore, 


\begin{tabular}{|c|c|c|c|c|}
\hline Code & Question Item & $\begin{array}{l}\text { No. of } \\
\text { Responses }\end{array}$ & $\begin{array}{l}\text { Top-Box } \\
\text { Responses }\end{array}$ & National Average \\
\hline \multirow[t]{2}{*}{$\mathrm{OHR}$} & Rate this hospital from 0 to 10 & 1470 & $78 \%$ & $73 \%$ \\
\hline & Communication w/ doctors & & & $82 \%$ overall \\
\hline Doctor-1 & Did doctors explain things in a way you could understand? & 1464 & $85 \%$ & \\
\hline Doctor-2 & Did doctors listen carefully to you? & 1464 & $87 \%$ & \\
\hline \multirow[t]{2}{*}{ Doctor-3 } & Did doctors treat you with courtesy and respect? & 1467 & $92 \%$ & \\
\hline & Communication about medicines & & & $65 \%$ overall \\
\hline Medication-1 & Did hospital staff describe possible side effects in a way you could understand? & 970 & $51 \%$ & \\
\hline \multirow[t]{2}{*}{ Medication-2 } & Did hospital staff tell you what the medicine was for? & 982 & $80 \%$ & \\
\hline & Communication w/ nurses & & & $80 \%$ overall \\
\hline Nursing-1 & Did nurses explain things in a way you could understand? & 1473 & $80 \%$ & \\
\hline Nursing-2 & Did nurses listen carefully to you? & 1468 & $78 \%$ & \\
\hline \multirow[t]{2}{*}{ Nursing-3 } & Did nurses treat you with courtesy and respect? & 1471 & $86 \%$ & \\
\hline & Discharge communication & & & \\
\hline Discharge-1 & $\begin{array}{l}\text { Did you get information in writing about what symptoms or health problems to } \\
\text { look out for after you left the hospital? }\end{array}$ & 1372 & $96 \%$ & $87 \%$ \\
\hline \multirow[t]{2}{*}{ Discharge-2 } & $\begin{array}{l}\text { Did doctors, nurses, or other hospital staff talk with you about whether you } \\
\text { would have the help you needed when you left the hospital? }\end{array}$ & 1373 & $92 \%$ & $52 \%$ \\
\hline & Hospital environment & & & \\
\hline Environment-1 & Were your room and bathroom kept clean? & 1462 & $71 \%$ & $75 \%$ \\
\hline \multirow[t]{2}{*}{ Environment-2 } & Was the area around your room quiet at night? & 1463 & $63 \%$ & $62 \%$ \\
\hline & Pain management & & & \\
\hline Pain-1 & Was your pain well controlled? & 1323 & $63 \%$ & $71 \%$ \\
\hline \multirow[t]{2}{*}{ Pain-2 } & Did the hospital staff do everything they could to help you with your pain? & 1321 & $81 \%$ & NA \\
\hline & Responsiveness & & & $69 \%$ overall \\
\hline Responsiveness-1 & After you pressed the call button, did you get help as soon as you wanted it? & 1285 & $63 \%$ & \\
\hline Responsiveness-2 & $\begin{array}{l}\text { Did you get help in getting to the bathroom or in using a bedpan as soon as you } \\
\text { wanted? }\end{array}$ & 1093 & $69 \%$ & \\
\hline
\end{tabular}

$\mathrm{NA}=$ not applicable.

this analysis is limited to those patients who responded..$^{11,12}$ The data were compiled and unified in Microsoft Excel, and all analyses were performed using RStudio software. A $p<0.05$ was considered statistically significant.

\section{Results \\ Participants}

The inclusion criteria generated 1478 patients distributed among the three hospitals and attended by 30 surgeons. After 8 patients were eliminated for not responding to the OHR item, 1470 patients remained in the analysis (Fig. 1). The overall quantity of responses and the percent of top-box responses are reported in Table 1. Among the attendings were 22 neurosurgeons and 8 orthopedic spine surgeons (Table 2). Most of the surgeons were men, and the overall mean experience was 27 years. Compared to the national average top-box scores, our institution outperformed the nation in OHR scores as well as on the Doctor and Discharge questions.

\section{Main Results}

The first analysis was performed to determine baseline differences in OHR based on hospital admission variables. In a multivariate logistic regression controlling for subspecialty and hospital type, every year of additional surgeon experience was associated with a significantly increased likelihood of patients reporting a top-box OHR (OR 1.02, 95\% CI 1.00-1.03; Table 3). Also, patients admitted to an orthopedic surgeon (OR $0.56,95 \%$ CI $0.40-0.77$ ) were less likely to give a top-box OHR.

The second analysis was performed to create a model, adjusted for the significant baseline variables in the first analysis and using backward elimination, that described which HCAHPS items had the strongest influence on the OHR. Among the 17 items tested, a total of 7 (Discharge-1, Nursing-3, Environment-1, Doctor-1, Responsiveness-1, Pain-2, Nursing-2) remained in the adjusted model (Table 4). Only two of those were related to the surgeon/surgical team: Discharge-1, "Did you get information in writing about what symptoms or health problems to look out for after you left the hospital?" (OR 5.93, 95\% CI 2.52-13.94); and Doctor-1, "Did doctors explain things in a way you could understand?" (OR 2.78, 95\% CI 1.73-4.46). The top three strongest correlating items were as follows: Discharge-1; Nursing-3, "Did nurses treat you with courtesy 


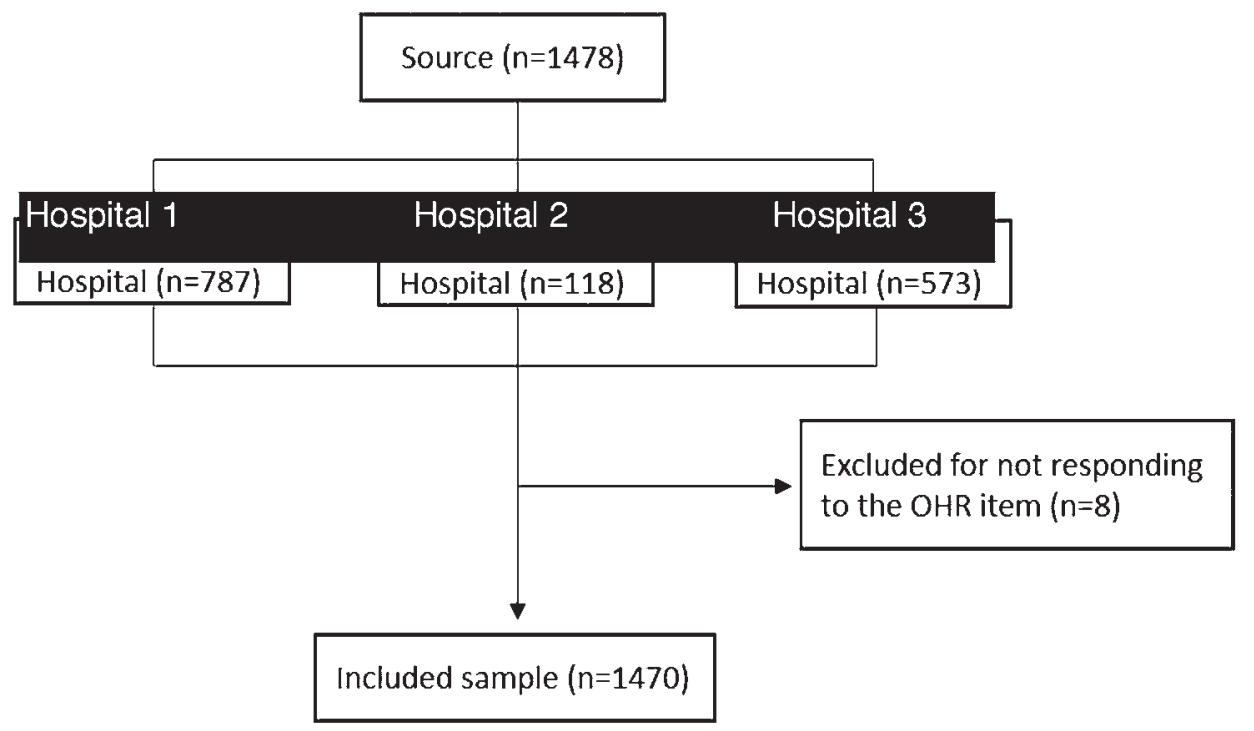

FIG. 1. Flow diagram of the study cohort.

and respect?" (OR 3.86, 95\% CI 2.28-6.52); and Environment-1, "Were your room and bathroom kept clean?" (OR $2.86,95 \%$ CI 1.96-4.17).

\section{Subgroup Analyses}

To investigate confounding, additional post hoc tests were run. Beta regression revealed that after controlling for hospital, the response rate to an item was significantly influenced by the score, indicating that HCAHPS items with higher overall scores were more likely to have had a response $\left(\mathrm{p}<0.001\right.$, pseudo $\left.\mathrm{R}^{2} 0.15\right)$.

\section{Discussion \\ Key Results}

This retrospective exploratory analysis of neurosurgical patient satisfaction data revealed that within our health system, surgical service and surgeon years of experience were significant factors affecting the OHR for HCAHPS.

TABLE 2. Characteristics among 30 surgeons

\begin{tabular}{cc}
\hline Variable & Value \\
\hline Specialty & \\
\hline Neurosurgery & $22(73.3)$ \\
\hline Cranial & 4 \\
\hline Pediatric & 3 \\
\hline Spine & 12 \\
\hline Vascular & 3 \\
\hline Orthopedics spine & $8(26.7)$ \\
\hline Male sex & $27(90)$ \\
\hline Experience in yrs & $13.0(11.3)$ \\
\hline
\end{tabular}

Continuous variables are expressed as the mean (SD). Categorical variables are expressed as the number (\%).
Once the HCAHPS factors affecting OHR were adjusted for, the HCAHPS items with the most influence on OHR were Discharge-1 ("Did you get information in writing about what symptoms or health problems to look out for after you left the hospital?"), Nursing-3 ("Did nurses treat you with courtesy and respect?"), and Environment-1 ("Were your room and bathroom kept clean?").

\section{Interpretation}

Our results indicate that out of the 7 items on the HCAHPS that predict OHR, only one of the top three questions that most significantly contributed to the OHR was related to the actions of the surgeons/surgical team. Hence, the HCAHPS's OHR minimally captures the patient assessment of communication with doctors and discharge communication, and there are significant competing contributions from communication with nurses and pain management as well.

Primarily, the fact that all the doctor or discharge communication items drop out as significant predictors in different subpopulations is important because it means that the HCAHPS OHR is not a specifically useful measure of neurosurgeon performance, but rather a reflection of whatever is left as a significant predictor. This does not mean that neurosurgeons should completely dissociate themselves from the OHR-instead, we should consider improving patient satisfaction with the quality of care as a group effort and encourage initiatives for change in domains that prove to be both significant drivers of OHR and weak performance areas. ${ }^{13-16}$

We should also consider measures other than HCAHPS to be tied to reimbursement. The relationship between patient satisfaction and what physicians consider to be measures of quality has always been controversial. ${ }^{17-22}$ In addition to the adjustment for nonresponse bias, HCAHPS scores must also be adjusted for the environment; it has been demonstrated that there are several hospital- and 
TABLE 3. Admission-specific determinants of OHR

\begin{tabular}{lccr}
\hline \multicolumn{1}{c}{ Variable } & OR & $95 \% \mathrm{Cl}$ & $\mathrm{p} \mathrm{Value}$ \\
\hline Orthopedics (ref = neurosurgery) & 0.56 & $0.40-0.77$ & $<0.01$ \\
\hline Experience (for every yr of experience) & 1.02 & $1.00-1.03$ & $\mathbf{0 . 0 3}$ \\
\hline Female (ref = male) & 1.38 & $0.70-2.75$ & 0.36 \\
\hline Month & 1.00 & $0.97-1.02$ & 0.81 \\
\hline
\end{tabular}

ref $=$ reference.

Boldface type indicates statistical significance. The first set of regressions looked at hospital data as predictors after controlling for subspecialty and hospital size. Patients of more experienced surgeons gave higher ratings.

county-level factors that confound the HCAHPS score, including case mix, illness severity, hospital size, and local demographics. ${ }^{23-31}$ However, care should be taken to ensure that over-adjustment does not lead to ignoring real differences in experiences between groups. ${ }^{32-34}$

Secondarily, it is important to note the variability in items that are the strongest drivers of OHR in different populations because it indicates that these same analyses must be done for any neurosurgical department that wishes to draw conclusions about the utility of the OHR. ${ }^{35,36} \mathrm{In}$ this regard, our findings agree with the results in more limited neurosurgical populations such as adult spine patients and adult cranial patients. ${ }^{37,38}$ Each microenvironment is unique, and our findings demonstrate that while trends exist, there are no hard rules about the OHR even within a single health system. Our specific findings should not be generalized to other neurosurgical hospital services but instead serve as a template for exploratory analyses to drive quality improvement.

This study has several limitations inherent to any retrospective review of voluntary survey data. The accuracy of HCAHPS data is limited by the response rate, a phenomenon well documented in the literature. ${ }^{11,39-41}$ Our study was no exception with a response rate of $16.3 \%$. There are also sources of bias in both incomplete HCAHPS surveys and unreturned surveys, as discussed above and as noted by our post hoc beta analysis. The variable return rates among the different hospitals can make it difficult to generalize the data. Limited access to patient data prevented the inclusion of other confounders noted in the literature, such as illness severity and race/ethnicity. Second, there may have been less variability among the 30 surgeons we followed, which could decrease variation in the factors that affect the resulting OHR. Third, HCAHPS requires at least 300 completed surveys per hospital to achieve a minimum of 0.8 reliability for the reported measures..$^{42}$ Because our study had 1470 filled questionnaires for 30 surgeons, averaging about 49 surveys per surgeon, the reliability for surgeon assessment may be low.

\section{Conclusions}

Our findings demonstrate that there are several factors and items not under the direct purview of the neurosurgeon (e.g., nursing communication, hospital environment) that are significant influences on inpatient satisfaction on the HCAHPS survey. This indicates that the HCAHPS
TABLE 4. HCAHPS items that predict OHR

\begin{tabular}{lccc}
\hline \multicolumn{1}{c}{ Variable } & OR & $95 \% \mathrm{Cl}$ & $\mathrm{p}$ Value \\
\hline Discharge-1 & $\mathbf{5 . 9 3}$ & $\mathbf{2 . 5 2 - 1 3 . 9 4}$ & $<0.01$ \\
\hline Nursing-3 & 3.86 & $2.28-6.52$ & $<0.01$ \\
\hline Environment-1 & 2.86 & $1.96-4.17$ & $<0.01$ \\
\hline Doctor-1 & $\mathbf{2 . 7 8}$ & $\mathbf{1 . 7 3 - 4 . 4 6}$ & $<0.01$ \\
\hline Responsiveness-1 & 2.48 & $1.67-3.67$ & $<0.01$ \\
\hline Pain-2 & 1.87 & $1.20-2.93$ & 0.01 \\
\hline Nursing-2 & 1.69 & $1.05-2.74$ & 0.03 \\
\hline
\end{tabular}

Corrected for admission-specific variables after controlling for subspecialty and hospital size. Of the 7 independently significant questions contributing to the overall rating, only 2 (Discharge-1 and Doctor-1) were directly related to the surgical team. Boldface type indicates items related to the surgeon/surgical team.

OHR is not a reliable measure of neurosurgical quality. Although the HCAHPS will continue to have value to the various dimensions of care represented in the survey, neurosurgeons and hospitals should consider alternative measures of performance, including both postoperative outcomes and patient satisfaction, and should work with other teams like nursing to improve overall patient satisfaction, even where the surgical team measures are not significant.

\section{Acknowledgments}

Research reported in this publication was supported by the National Center for Advancing Translational Sciences of the National Institutes of Health under Award No. TL1TR001116.

\section{References}

1. Zusman EE. HCAHPS replaces Press Ganey survey as quality measure for patient hospital experience. Neurosurgery. 2012;71(2):N21-N24.

2. High Quality Care for All: NHS Next Stage Review Final Report. Department of Health (UK); 2008. Accessed May 28, 2020. https://www.gov.uk/government/publications/highquality-care-for-all-nhs-next-stage-review-final-report

3. Beattie M, Murphy DJ, Atherton I, Lauder W. Instruments to measure patient experience of healthcare quality in hospitals: a systematic review. Syst Rev. 2015;4:97.

4. Daly R. Unsatisfactory marks. Hospitals question use of HCAHPS in scoring for value-based purchasing. Mod Healthc. 2011;41(33):30.

5. Elliott MN, Beckett MK, Lehrman WG, et al. Understanding the role played by Medicare's Patient Experience Points System in hospital reimbursement. Health Aff (Millwood). 2016; 35(9):1673-1680.

6. Patient survey (HCAHPS) - National. Data.Medicare.Gov. Accessed May 28, 2020. https://data.medicare.gov/HospitalCompare/Patient-survey-HCAHPS-National/99ue-w85f/data

7. Vandenbroucke JP, von Elm E, Altman DG, et al. Strengthening the Reporting of Observational Studies in Epidemiology (STROBE): explanation and elaboration. Int J Surg. 2014; 12(12):1500-1524.

8. HCAHPS Frequently Asked Questions. Press Ganey. August 9, 2019. Accessed May 28, 2020. http://www.pressganey.com/ resources/program-summary/frequently-asked-questionsabout-hcahps

9. Summary of HCAHPS Survey Results. April 2016 to March 
2017 Discharges. Centers for Medicare \& Medicaid Services. December 21, 2017. Accessed May 28, 2020. https://www. hcahpsonline.org/globalassets/hcahps/summary-analyses/ results/2017-12_summary-analyses_state-results.pdf

10. Elliott MN, Edwards C, Angeles J, et al. Patterns of unit and item nonresponse in the CAHPS Hospital Survey. Health Serv Res. 2005;40(6 Pt 2):2096-2119.

11. Perneger TV, Chamot E, Bovier PA. Nonresponse bias in a survey of patient perceptions of hospital care. Med Care. 2005;43(4):374-380.

12. Kessler RC, Little RJ, Groves RM. Advances in strategies for minimizing and adjusting for survey nonresponse. Epidemiol Rev. 1995;17(1):192-204.

13. Hoyt DB, Ko CY, Jones RS. Optimal Resources for Surgical Quality and Safety. American College of Surgeons; 2017.

14. Rose D, Garneski S. ACS releases new manual to guide surgeons in leading quality improvement efforts. American College of Surgeons. August 7, 2017. Accessed August 31, 2018. https://www.facs.org/media/press-releases/2017/qualitymanual080717

15. Welton JM. Implications of Medicare reimbursement changes related to inpatient nursing care quality. J Nurs Adm. 2008; 38(7-8):325-330.

16. Kliot T, Zygourakis CC, Imershein S, et al. The impact of a patient education bundle on neurosurgery patient satisfaction. Surg Neurol Int. 2015;6(22)(suppl 22):S567-S572.

17. Sacks GD, Lawson EH, Dawes AJ, et al. Relationship between hospital performance on a patient satisfaction survey and surgical quality. JAMA Surg. 2015;150(9):858-864.

18. Asprey A, Campbell JL, Newbould J, et al. Challenges to the credibility of patient feedback in primary healthcare settings: a qualitative study. Br J Gen Pract. 2013;63(608):e200-e208.

19. Riskind P, Fossey L, Brill K. Why measure patient satisfaction? J Med Pract Manage. 2011;26(4):217-220.

20. Levin JM, Winkelman RD, Smith GA, et al. The association between the Hospital Consumer Assessment of Healthcare Providers and Systems (HCAHPS) survey and real-world clinical outcomes in lumbar spine surgery. Spine J. 2017; 17(11):1586-1593.

21. Godil SS, Parker SL, Zuckerman SL, et al. Determining the quality and effectiveness of surgical spine care: patient satisfaction is not a valid proxy. Spine J. 2013;13(9):1006-1012.

22. Glickman SW, Schulman KA. The mis-measure of physician performance. Am J Manag Care. 2013;19(10):782-785.

23. Elliott MN, Zaslavsky AM, Goldstein E, et al. Effects of survey mode, patient mix, and nonresponse on CAHPS hospital survey scores. Health Serv Res. 2009;44(2 Pt 1):501-518.

24. Siddiqui ZK, Wu AW, Kurbanova N, Qayyum R. Comparison of Hospital Consumer Assessment of Healthcare Providers and Systems patient satisfaction scores for specialty hospitals and general medical hospitals: confounding effect of survey response rate. J Hosp Med. 2014;9(9):590-593.

25. Thiels CA, Hanson KT, Yost KJ, et al. Effect of hospital case mix on the hospital consumer assessment of healthcare providers and systems star scores: are all stars the same? Ann Surg. 2016;264(4):666-673.

26. Merlino JI, Kestranek C, Bokar D, et al. HCAHPS survey results: impact of severity of illness on hospitals' performance on HCAHPS survey results. J Patient Exp. 2014;1(2):16-21.

27. McFarland DC, Ornstein KA, Holcombe RF. Demographic factors and hospital size predict patient satisfaction variance-implications for hospital value-based purchasing. $J$ Hosp Med. 2015;10(8):503-509.

28. McFarland DC, Shen MJ, Parker P, et al. Does hospital size affect patient satisfaction? Qual Manag Health Care. 2017; 26(4):205-209.

29. McFarland DC, Johnson Shen M, Holcombe RF. Predictors of satisfaction with doctor and nurse communication: a national study. Health Commun. 2017;32(10):1217-1224.
30. Iannuzzi JC, Kahn SA, Zhang L, et al. Getting satisfaction: drivers of surgical Hospital Consumer Assessment of Health care Providers and Systems survey scores. J Surg Res. 2015; 197(1):155-161.

31. Kahn SA, Iannuzzi JC, Stassen NA, et al. Measuring satisfaction: factors that drive hospital consumer assessment of healthcare providers and systems survey responses in a trauma and acute care surgery population. Am Surg. 2015; 81(5):537-543.

32. Hasnain M, Schwartz A, Girotti J, et al. Differences in patient-reported experiences of care by race and acculturation status. J Immigr Minor Health. 2013;15(3):517-524.

33. Murray-García JL, Selby JV, Schmittdiel J, et al. Racial and ethnic differences in a patient survey: patients' values, ratings, and reports regarding physician primary care performance in a large health maintenance organization. Med Care. 2000;38(3):300-310.

34. Mead N, Roland M. Understanding why some ethnic minority patients evaluate medical care more negatively than white patients: a cross sectional analysis of a routine patient survey in English general practices. BMJ. 2009;339:b3450.

35. Finney JW, Humphreys K, Kivlahan DR, Harris AHS. Why health care process performance measures can have different relationships to outcomes for patients and hospitals: understanding the ecological fallacy. Am J Public Health. 2011; 101(9):1635-1642.

36. Finney JW, Humphreys K, Kivlahan DR, Harris AHS. Excellent patient care processes in poor hospitals? Why hospitallevel and patient-level care quality-outcome relationships can differ. J Gen Intern Med. 2016;31(suppl 1):74-77.

37. Levin JM, Winkelman RD, Tanenbaum JE, et al. Key drivers of patient satisfaction in lumbar spine surgery. J Neurosurg Spine. 2018;28(6):586-592.

38. Kerezoudis P, Alvi MA, Ubl DS, et al. The impact of spine disease, relative to cranial disease, on perception of health and care experience: an analysis of 1484 patients in a tertiary center. J Neurosurg. 2018;129(6):1630-1640.

39. Barr DA, Vergun P. Using a new method of gathering patient satisfaction data to assess the effects of organizational factors on primary care quality. Jt Comm J Qual Improv. 2000; 26(12):713-723.

40. Gribble RK, Haupt C. Quantitative and qualitative differences between handout and mailed patient satisfaction surveys. Med Care. 2005;43(3):276-281.

41. Drake KM, Hargraves JL, Lloyd S, et al. The effect of response scale, administration mode, and format on responses to the CAHPS Clinician and Group survey. Health Serv Res. 2014;49(4):1387-1399.

42. Giordano LA, Elliott MN, Goldstein E, et al. Development, implementation, and public reporting of the HCAHPS survey. Med Care Res Rev. 2010;67(1):27-37.

\section{Disclosures}

Dr. Gottfried is a medical consultant for Pioneer Surgical Technology Inc. The content of this paper is solely the responsibility of the authors and does not necessarily represent the official views of the National Institutes of Health.

\section{Author Contributions}

Conception and design: Gottfried, Zakare-Fagbamila. Acquisition of data: Gottfried, Zakare-Fagbamila, Dickson, Garcia. Analysis and interpretation of data: Gottfried, Park, Zakare-Fagbamila. Drafting the article: Gottfried, Park, Zakare-Fagbamila. Critically revising the article: Park. Reviewed submitted version of manuscript: Gottfried, Park. Statistical analysis: Zakare-Fagbamila. Administrative/technical/material support: Park. Study supervision: Gottfried. 


\section{Supplemental Information}

Previous Presentations

Portions of this work were presented as oral presentations at the North American Spine Society 34th Annual Meeting held in

Chicago, Illinois, on September 25-28, 2019, and at the Spine

Summit-35th Annual Meeting of the Section on Disorders of the

Spine and Peripheral Nerves held in Miami, Florida, on March 14-17, 2019.

\section{Correspondence}

Oren N. Gottfried: Duke University School of Medicine, Durham, NC. oren.gottfried@duke.edu. 